\title{
1 Advancing Rhodobacter sphaeroides as a platform for expression of functional membrane
}

2 proteins

Running title: Functional membrane proteins from Rhodobacter

Mustafa Erbakan ${ }^{1}:+1.814 .777 .6931$, mxe198@psu.edu

$7 \quad$ Brandon S. Curtis ${ }^{2}:+1.424 .108 .8510$, brandon.curtis@berkeley.edu

B. Tracy Nixon ${ }^{3}:+1.814 .863 .4904$, btn1@psu.edu

Manish Kumar ${ }^{4}:+1.814 .865 .7519$, manish.kumar@psu.edu

Author affiliations:

13 1) Department of Biomedical Engineering, The Pennsylvania State University, University Park, $14 \quad$ PA. 16802

2) Department of Chemical and Biomolecular Engineering, University of California at Berkeley, 16 Berkeley, CA, 94720-1462.

17 3) Department of Biochemistry and Molecular Biology, The Pennsylvania State University, 18 University Park, PA 16802,

19 4) Department of Chemical Engineering, The Pennsylvania State University, University Park, 20 PA 16802.

\section{Correspondence to:}

22 Wayne R. Curtis, Professor of Chemical Engineering, The Pennsylvania State University, 23 University Park, PA 16802-4400. Phone: +1.814.863.4805, Fax: 1.814.865.7846, email:

24 wrc2@psu.edu. 
ABSTRACT

Membrane protein overexpression is often hindered by toxic effects on the expression

34 host, limiting achievable volumetric productivity. Moreover, protein structure and function may

35 be impaired due to inclusion body formation and proteolytic degradation. To address these

36 challenges, we employed the photosynthetic bacterium, Rhodobacter sphaeroides for expression

37 of challenging membrane proteins including human aquaporin 9 (hAQP9), human tight junction

38 protein occludin (Occ), E. coli toxin peptide GhoT, cellulose synthase enzyme complex (BcsAB)

39 of $R$. sphaeroides and cytochrome-cy (Cyt-cy) from R. capsulatus. Titers of $47 \mathrm{mg} / \mathrm{L}$ for Cyt-cy,

$40 \quad 7.5 \mathrm{mg} / \mathrm{L}$ for Occ, $1.5 \mathrm{mg} / \mathrm{L}$ for BcsAB and $0.5 \mathrm{mg} / \mathrm{L}$ for hAQP9 were achieved from affinity

41 purification. While purification of GhoT was not successful, transformants displayed a distinct

42 growth phenotype that correlated with GhoT expression. We also evaluated the functionality of

43 these proteins by performing water transport studies for hAQP9, peroxidase activity for

44 cytochrome-cy, and in vitro cellulose synthesis activity assay for BcsAB. While previous studies

45 with Rhodobacter have utilized oxygen-limited semi-aerobic growth for membrane protein

46 expression. Substantial titer improvements are achieved as a result of a 3 -fold increase in

47 biomass yield using the anaerobic photoheterotrophic growth regime, which utilizes the strong

48 native puc promoter. This versatile platform is shown to enable recovery of a wide variety of

49 difficult-to-express membrane proteins in functional form.

50 KEYWORDS: Rhodobacter sphaeroides, cytochrome, aquaporin, cellulose synthase, toxin-

51 antitoxin, anaerobic photohetotrophic growth, membrane protein. 
INTRODUCTION

Membrane proteins (MPs) play critical physiological roles in all biological cells

55 including selective transport of solutes, signal transduction, energy generation, cell-cell adhesion

56 and motility (Link and Georgiou, 2007). Typically, 30\% of any genome encodes for MPs

57 (Stevens and Arkin, 2000). Despite being of crucial importance, MPs are underrepresented in

58 protein structural databases compared to soluble proteins. According to RSCB Protein Data Bank

59 (http://www.rcsb.org/pdb/home/home.do) nearly 108,000 protein structures are available from

60 different protein families including roughly 9,800 soluble protein classes (Laible et al., 2009). By

61 comparison, the "Membrane proteins of known 3D structure" database

62 (http://blanco.biomol.uci.edu/mpstruc/) indicates 539 unique families identified from 1654 total

63 number of MP structures, where the vast majority of these are of bacterial and archaeal origin.

64 Structural data for MPs facilitate more detailed understanding of mechanisms of action, which is

65 crucial to human health, as more than $60 \%$ of the FDA approved drugs target MPs (Yildirim et

66 al., 2007). Availability of MPs is also desired for high throughput drug screening (Lundstrom,

67 2004), biotechnological (Nielsen, 2009) and biomedical applications (Majd et al., 2010).

68 Most MPs are available in only very limited quantities from natural sources, necessitating

69 recombinant expression for further study. A variety of prokaryotic and eukaryotic expression

70 systems have been employed for recombinant MP expression (Bernaudat et al., 2011; Nielsen,

71 2009; Sarramegna et al., 2003). While eukaryotic systems employing yeast, insect, or

72 mammalian cells are the inevitable choice for proteins requiring significant post-translational

73 modification; prokaryotic systems offer advantages in ease of genetic manipulation, rapid

74 growth, and inexpensive culturing (Laible et al. 2011). E. coli is the most common protein

75 expression system for proteins not undergoing post-translational modifications; however MP 
expression titers in E.coli remain one to two orders of magnitude lower than for soluble proteins

77 (Tate, 2001). A major challenge to MP expression in E. coli is limited membrane area to accommodate overexpressed MPs forcing them into inclusion bodies in which native MP

79 structure and function are lost (Arechaga et al., 2000).

To address these issues, we employed a facultatively anaerobic phototrophic purple

81 bacterium, Rhodobacter sphaeroides 2.4.1, for functional expression of challenging MPs. The most striking feature of the Rhodobacter species relevant to MP expression is the presence of an

83 extensive network of intracellular photosynthetic membranes (ICMs) that, when induced by

84 reduced oxygen tension $(0.5-2 \%)$ and low light intensity $\left(\sim 4 \mathrm{~W} / \mathrm{m}^{2}\right)$, increase cellular membrane

85 surface area by more than an order of magnitude (Adams and Hunter, 2012; Drews and Golecki,

86 1995). ICM formation is therefore concomitant with the synthesis of the photosynthetic

87 apparatus (Zeilstra-Ryalls et al., 1998). The Rhodobacter photosystem is comprised of the

88 photosynthetic reaction center (RC) surrounded by first- and second-tier light harvesting

89 antennae (LH1 and LH2) (Sener et al., 2007). RC and LH1 are expressed from the puf operon in

90 response to reduced oxygen tension. LH2 is expressed from the puc operon in response to

91 reduced oxygen tension and reduced light intensity.

92 Previous work has demonstrated improved heterologous MP expression titers by

93 knocking out some or all of the photosynthetic complex proteins, possibly by increasing the

94 available ICM area (Hanson et al., 2009). Protein expression in this system is most commonly

95 driven by the puf promoter with semi-aerobic induction (Laible et al., 2004; Laible et al., 2009;

96 Roy et al., 2008) utilization of the puf promoter is motivated in part by the ease of implementing

97 'semi-aerobic' growth in oxygen-limited shake flask cultures. Although expression driven by the 98 puc promoter in the anaerobic photohetereotrophic growth regime has met with limited success 
99 (Bernaudat et al., 2011), this growth mode has the greatest promise for exploiting the unique 100 physiological properties of Rhodobacter. Cellular concentrations of LH2 driven by the puc

101 promoter can exceed 5\% of dry weight, and are significantly higher than the concentrations of

102 RC-LH1 complexes and ICM under anaerobic photoheterotrophic conditions (Remsen, 1978).

103 Knocking out LH2 frees up membrane surface area in the ICM while retaining the ability to 104 grow photoheterotrophically. In this study, our results substantiate this approach, since anaerobic 105 photoheterotrophic cultures reached 3-4 times higher biomass yield compared to semi-aerobic 106 cultures while experiencing no loss in specific MP productivity. Considering these advantages, 107 we optimized promoter induction under anaerobic photoheterotrophic conditions and 108 demonstrated the versatility of the system for functionally expressing MPs from various sources 109 and levels of complexity.

\section{MATERIALS AND METHODS}

\section{Culturing Conditions}

Anaerobic photoheterotrophic Rhodobacter cultures were grown in $750 \mathrm{~mL}$ T-flasks

114 under a bank of infrared LEDs with a peak wavelength of $850 \mathrm{~nm}\left(4 \mathrm{~W} / \mathrm{m}^{2}\right.$, Snowdragon

115 Industrial Co. Ltd, Shenzhen, China). A schematic and picture of the relatively simple

116 experimental appratus is shown in Figure 1. Temperature was mainted by partial submergence in

117 a plastic storage container on a stir plate with a stir-bar inside the completely filled T-flask for

118 mixing. . To maintain consistency across batches with different levels of pigmentation, the

119 optical density was measured via Spectramax Plus 384 spectrophotometer (Molecular Devices,

120 Sunnyvale CA) at $660 \mathrm{~nm}$ to avoid interference by photosynthetic pigments (Myers et al., 2013).

\section{Measurement of Growth Kinetics and Biomass Yield}


$8 \mathrm{~mL}$ of semi-aerobic cultures were grown in $25 \mathrm{~mm}$ culture tubes in gyratory shaker at

$12332^{\circ} \mathrm{C}$, while $8 \mathrm{~mL}$ photoheterotrophic cultures were grown in $1 \mathrm{~cm}$ diameter screwcap culture

124 tubes mounted in a stellate pattern on a rotator (perpendicular to the $45^{\circ}$ rotating access) such

125 that the small gas space would move up and down the tube during rotation at 15 RPM. Growth

126 in these $\sim 1 \mathrm{~cm}$ diameter culture tubes enabled $\mathrm{OD}_{660}$ measurements within the

127 spectrophotometer (Curtis, 2011). The cultures were grown until the stationary phase by

128 measuring $\mathrm{OD}_{660}$ every 3 hours. For biomass yield measurements, $5 \mathrm{~mL}$ culture was spun down

129 at $15,000 \mathrm{xg}$, washed twice in $1.6 \mathrm{~mL}$ microfuge tubes with tap water instead of deionized water

130 to avoid cell lysis and lyophilized at least for 24 hours in a pretared tube.

\section{Molecular Biology and Specific Constructs}

132 Vector constructs used in this study are listed in Table I. All of the target genes were 133 cloned between unique ${ }^{5}$ SpeI and $\mathrm{BgIII}^{3}$ ' enzyme sites in $p R K P L H T 1 \& 7$ vectors to introduce

$1347 x$ His-tag from the vector backbone to the C-termini of target MPs. The native aquaporin of 135 Rhodobacter sphaeroides, RsAqpZ (Genbank id: ABA78939), was included as a positive control

136 for expression level between the constructs (Erbakan et al., 2014). Rhodobacter sphaeroides

137 2.4.1 codon optimized genes for human aquaporin 9 (Genbank id: NP_066190), as well as

138 transmembrane and C-terminus of human occludin (Genbank id: AAH29886) were purchased

139 from Genscript Inc., Piscataway, NJ. pET28b-ghoT vector, kindly provided by Dr. Thomas

140 Wood was used for cloning ghoT (Genbank id: BAE78131) into the $p R K P L H T 7$ vector. BcsAB

141 complex was cloned into $p R K P L H T 7$ vector as a polycystronic gene using in-fusion cloning kit

142 (Clontech Laboratories, Inc., Mountainview, CA). bcsA (Genbank id: ABA79509) and $b c s B$

143 (Genbank id: ABA79508) genes were PCR amplified from genomic DNA with primers having

14415 bp overlaps to the vector backbone. A $12 x H i s-t a g$ sequence and a stop codon was placed in 
145 the downstream $b c s A$ gene to generate a C-terminally His-tagged version of BcsA subunit for

146 affinity purification of the protein complex as described previously (Morgan et al., 2013). Start

147 codon of $b c s B$ was immediately after $b c s A$ stop codon and an additional stop codon was included

148 within the $b c s B$ reverse primer to prevent the addition of a vector-encoded 7xHis-tag to its C-

149 terminus.

\section{Protein Purification}

For purification of hAQP9, Cyt-cy, RsAqpZ, Occludin and GhoT, a detailed protein

152 purification protocol was described elsewhere (Erbakan et al., 2014). The minor modifications

153 employed for purification of BcsAB are described here: BcsAB lysis buffer contained $20 \mathrm{mM}$

154 Tris at $\mathrm{pH}=7.2,1 \mathrm{mM} \mathrm{MgCl} 2,5 \mathrm{mM}$ cellobiose, $10 \mathrm{mM}$ imidazole, $1 \mathrm{mM}$ PMSF, $0.1 \mathrm{mg} / \mathrm{mL}$

155 DNAse, $0.02 \mathrm{mg} / \mathrm{mL}$ RNAse, and $1 \mathrm{mg} / \mathrm{mL}$ lysozyme. Solubilization buffer used to purify the

156 BcsAB complex had 1\% n-dodecyl $\beta$-D-maltoside (DDM) (Anatrace, Maumee, OH), and 1\%

157 n,n-dimethyldodecylamine n-oxide (LDAO) (Anatrace, Maumee, OH) on $0.5 \mathrm{~mL}$ Co-NTA resin

158 (1 mL slurry) (Thermo Fisher Scientific Inc.). Non-specific binding to the column was removed

159 by washing with 30 bed volumes of buffer containing $20 \mathrm{mM}$ Tris at $\mathrm{pH}=7.2,0.05 \% \mathrm{DDM}, 5$

$160 \mathrm{mM} \mathrm{MgCl}_{2}, 5 \mathrm{mM}$ cellobiose, $300 \mathrm{mM} \mathrm{NaCl}, 10 \%$ glycerol and imidazole at concentrations

161 ranging between 10-50 mM. For elution of BcsAB complex imidazole concentration in wash

162 buffer was increased to $1 \mathrm{M}$. Gel filtration chromatography was performed to further purify the

163 eluted fractions from Co-NTA resin with the same buffer devoid of imidazole.

\section{Functional Assays}

165 Water Transport Assay: Water transport activity of hAQP9 was measured in proteoliposomes

166 using stopped-flow light scattering technique as described elsewhere (Erbakan et al., 2014). The

167 light scattering traces were fit to double exponential rise curves to obtain the water transport rate 
168

169

170

171

172

173

174

175

176

177

178

179

180

181

182

183

184

185

186

187

188

189

constant k. Permeability of control liposomes and hAQP9 proteoliposomes were calculated using the following equation:

$$
P_{f}=\frac{k}{\left(S / V_{o}\right) \cdot V_{H_{2} O} \cdot \Delta \pi}
$$

where $\mathrm{S} / \mathrm{V}_{0}$ is the initial surface area to volume ratio of the vesicles, $\mathrm{V}_{\text {H2O }}$ the molar volume of water and $\Delta \pi$ is the applied osmotic gradient.

Cytochrome-cy Peroxidase Activity: Cytochrome-cy peroxidase activity was measured using Single Component TMB Peroxidase EIA Substrate Kit (Bio-Rad Laboratories Inc, Hercules, CA) according to the instructions of the manufacturer using Spectramax Plus 384 spectrophotometer (Molecular Devices, Sunnyvale CA). The kinetics of the reaction between $\mathrm{H}_{2} \mathrm{O}_{2}$ and TMB was monitored by shifting of the absorbance maximum of TMB from 280 to 655 $\mathrm{nm}$, which corresponds to the enzymatic activity of Cyt -cy. The extinction coefficient of oxidized TMB ( $\left.39000 \mathrm{M}^{-1} \mathrm{~cm}^{-1}\right)$ was used to calculate the specific activity of Cyt-cy in nmol $\mathrm{H}_{2} \mathrm{O}_{2}$ reduced/min/ $/ \mu \mathrm{mol}$ Cyt-cy. Inhibition test of peroxidase activity for Cyt-cy was performed with $1 \mathrm{mM}$ and $5 \mathrm{mM}$ sodium azide, as a radical scavenger (Kim et al., 2004).

BcsAB in-vitro Cellulose Synthesis: The activity of in vitro cellulose synthesis by Bcs AB complex was evaluated using the UDP-C ${ }^{14}$-glucose incorporation assay (Brown et al., 2012; Omadjela et al., 2013). The controls were devoid of either BcsAB complex or cyclic di-GMP. For the treatment, $0.3 \mu \mathrm{mol}$ of purified $\mathrm{Bcs} A \mathrm{~B}$ complex was incubated with a reaction mixture of $300 \mu \mathrm{L}$ containing $0.5 \mathrm{mM}$ Tris at $\mathrm{pH}=7.5,1 \mathrm{mM}$ UDP-glucose, $1 \mu \mathrm{M}$ UDP-C ${ }^{14}$-glucose, $20 \mathrm{mM}$ $\mathrm{MgCl}_{2}, 5 \mathrm{mM}$ cellobiose, at $30^{\circ} \mathrm{C}$ for $30 \mathrm{~min}$. The reaction was stopped by addition of $2 \%$ sodium dodecyl sulfate (SDS). The unincorporated UDP-C $\mathrm{C}^{14}$-glucose was removed by transferring the reaction mixture onto a glass filter and washing with $15 \mathrm{~mL}$ of $0.5 \mathrm{mM}$ Tris 
190 buffer at $\mathrm{pH}=7.5$. The scintillation counts were measured overnight and the results were

191 expressed as nmol UDP-glucose incorporated per minute per mg of BcsAB complex.

192 GhoT Activity: A phenotype change upon expression of the GhoT toxin was observed growing

193 the Rhodobacter YCC-tetl agar plates under semi-aerobic and photoheterotrophic conditions.

194 Rhodobacter strains expressing native and less toxic GhoTF38R mutant (Cheng et al., 2014)

195 from pRKPLHT7 vector were used. Due to protein expression from the puc promoter, which is

196 most active for anaerobic photosynthetic growth, semi-aerobic growth can be used to observe

197 reduced toxicity during lower expression. We streaked empty vector strain (control),

198 pRKPLHT7-GhoTF38R and pRKPLHT7-GhoT strains on YCC-Tet (1mg tet/L) agar plates and

199 grew either semi-aerobically in a $34^{\circ} \mathrm{C}$ incubator or photoheterotrophically under infrared LEDs

200 in an anaerobic growth chamber.

201

202 RESULTS

\section{Choice of Growth Mode}

204 LH2 knockout cells $(P U C 705-B A)$ with and without expression plasmids for RsAqpZ and

205 Occludin were grown both semi-aerobically and photoheterotrophically as described. Biomass

206 yields for photoheterotrophic cultures were up to four times higher compared to semi-aerobic

207 cultures despite the initial lag phase (Fig. 2A, 2B). Moreover, the specific protein expression

208 level remained comparable for both growth modes, leading to a much higher volumetric

209 productivity for photoheterotrophic cultures. Therefore, this study focused on using a technique

210 to take advantage of photoheterotrophic conditions for protein expression. 


\section{Protein Expression and Functional Activity Results}

$214 \quad$ Rhodobacter capsulatus Cytochrome-cy

215 Membrane bound cytochrome-cy from Rhodobacter capsulatus is involved in electron

216 transfer during photosynthesis and aerobic respiration (Jenney and Daldal, 1993). Expression

217 levels as high as $50 \mathrm{mg} / \mathrm{L}$ have been reported for this protein (Laible et al., 2009), although

218 functionality was not evaluated. SDS-PAGE (Fig. 3A) and Western-Blot (Fig. 3B) analysis

219 demonstrated abundant expression under photoheterotrophic conditions.

220 Cyt-cy peroxidase activity was measured to evaluate its functionality. The extent of the

221 reaction between hydrogen peroxide and 3,3',5,5'-tetramethylbenzidine (TMB) is monitored by

222 absorbance at $655 \mathrm{~nm}$ corresponding to oxidized product; 3,3',5,5'-tetramethylbenzidine

223 diimine. Time-dependent oxidation of TMB was proportional to cyt-cy concentration

224 demonstrating that cyt-cy was active (Fig. 4A). Cyt-cy had a specific activity of $1.18 \pm 0.38$

$225 \mathrm{nmol} \mathrm{H}_{2} \mathrm{O}_{2} / \mathrm{min} / \mu \mathrm{mol}$ cyt-cy, which is close to the reported value for soluble c-type cytochromes

226 (Kim et al. 2004) (Fig. 4B). The peroxidase activity was quenched to $25 \%$ of the maximum value

$227\left(0.31 \pm 0.07 \mathrm{nmol} \mathrm{H} \mathrm{O}_{2} / \mathrm{min} / \mu \mathrm{mol}\right.$ cyt-cy) by $5 \mathrm{mM}$ sodium azide (Fig. 4C), showing that the

228 presence of a free-radical scavenger decreased cytochrome-mediated oxidation of TMB.

\section{Rhodobacter Cellulose Synthase, BcsAB}

$\mathrm{Bcs} \mathrm{AB}$ is a membrane-associated cellulose synthase complex composed of BcsA and

231 BcsB subunits. BcsA is an integral MP with 8 transmembrane $\alpha$-helices and a cytosolic glycosyl

232 transferase domain. The C-terminal $\alpha$-helix of BcsB associates with transmembrane $\alpha$-helices of

233 BcsA to form the active complex, while the remaining portion of the protein, which is formed by

234 several $\alpha$-helix and $\beta$-sheet domains, resides in the periplasmic space. In Rhodobacter

235 sphaeroides, $\mathrm{B} c \mathrm{~A}$ and $\mathrm{B} c \mathrm{~B}$ subunits are expressed as a polycistronic message; we employed 10 
236 the same strategy in our photosynthetic expression system, with the addition of a 12-His tag to

237 the C-terminus of BcsA to facilitate purification by metal affinity chromatography. BcsAB

238 complex was purified from the membrane fraction of Rhodobacter with metal affinity and gel

239 filtration chromatography, which effectively removed smaller contaminating proteins while also

240 resolving a $50 \mathrm{kDa}$ band that was identified by mass spectrometry as a S41 type peptidase

241 (uniprot id: Q3IZC0). These purification steps yielded $1.5 \mathrm{mg}$ BcsAB per liter of culture at an

$242 \mathrm{OD}_{660}$ of 5 , which corresponds to $0.5 \mathrm{mg} \mathrm{BcsAB} / \mathrm{g}$ cells. In 10\% SDS-PAGE gel, oxidized BcsB

243 migrates at $100 \mathrm{kDa}$ while BcsA migrates at $80 \mathrm{kDa}$ as confirmed by LC/MS tandem mass

244 spectroscopy, which is in accordance with the previous reports (Omadjela et al., 2013). Since

245 only BcsA contains the His-tag to bind to the affinity resin, co-purification of BcsA and BcsB

246 subunits at comparable molar ratio as shown in the subsequent SDS-PAGE gel in Fig. 5A

247 indicates the purification of $\mathrm{B} \operatorname{cs} \mathrm{A}$ and $\mathrm{B} \operatorname{csB}$ in form of $\mathrm{B} \operatorname{cs} \mathrm{AB}$ complex. Western blotting with

248 His-tag antibody detected a band at $80 \mathrm{kDa}$ corresponding to BcsA-12xHis monomer (Fig. 5A).

249 In vitro cellulose synthesis activity of BcsAB was evaluated in solution using a UDP-C ${ }^{14}$ -

250 glucose incorporation assay in the presence or absence of cyclic di-GMP. Consistent with the

251 known regulation of this cellulose synthase (Morgan et al., 2014), cyclic di-GMP controlled

252 enzyme activity in an allosteric manner (Fig. 5B). The background scintillation count in the

253 absence of BcsAB was subtracted from both treatments with and without cyclic di-GMP. The

254 amount of incorporated UDP-C $\mathrm{C}^{14}$-glucose was almost two orders of magnitude higher with cyclic

255 di-GMP treatment, clearly demonstrating a functional BcsAB glucose polymerization activity.

256 The specific activity of BcsAB measured in detergent micelles was $58 \mathrm{nmol} / \mathrm{mg} \mathrm{BcsAB} / \mathrm{min}$,

257 which was an order of magnitude lower than the published specific activity measured in an

258 alternative of proteoliposomes (Omadjela et al., 2013). 


\section{Aquaporin 9}

Human aquaporin 9 (hAQP9) belongs to a large family of channel forming porin

261 proteins. It has 6 transmembrane $\alpha$-helices with two asparagine-proline-alanine (NPA) signature

262 motifs contributing to its hourglass structure. Human aquaporin 9 was overexpressed to generate

$2630.2 \mathrm{mg} / \mathrm{L}$ purified protein. The expression was verified with the presence of monomeric and

264 tetrameric form of the protein at 28 and $60 \mathrm{kDa}$ respectively, which were detected by both SDS-

265 PAGE and Western-blot using a 4-12\% Nu-PAGE Tris-glycine gradient gel (Life Technologies,

266 Grand Island, NY) (Fig. 6). The monomeric form of hAQP9 ran slightly faster on SDS-PAGE

267 gel, which is typical for MPs due to increased SDS binding stoichiometry per amino acid residue

268 (Rath et al., 2009). On the other hand, hAQP9 tetramer showed a significantly increased

269 mobility, which was possibly due to the compact structure of the intact tetrameric form and well

270 documented in the literature for other aquaporins (Borgnia et al. 1999; Erbakan et al. 2014). The

271 water permeability was directly proportional to the quantity of hAQP9 in proteoliposomes (Fig.

272 7), thereby confirming functional transport of $\mathrm{H}_{2} \mathrm{O}$ into vesicles by the heterologously expressed

273 and purified aquaporin.

274

275

\section{Occludin}

Occludin is a tight junction protein with 4 transmembrane $\alpha$-helices forming two

277 extracellular and one intracellular loop. Extracellular loops from adjacent cells bind strongly to

278 contribute to formation of the tight junction barrier. A codon-optimized human occludin gene

279 corresponding to last 474 amino acids of the protein encompassing the transmembrane and C-

280 terminal region was expressed in Rhodobacter at $7.5 \mathrm{mg} / \mathrm{L}$ as evidenced by SDS-PAGE and

281 Western-blotting (Fig. 8). Unlike other target proteins in this study, occludin lacks an ezymatic 
282 or transport activity, which makes it difficult to assess the functionality of the protein. An

283 attempt at quantifying occludin-mediated proteoliposome aggregation by dynamic light

284 scattering was not successful.

285

Escherichia coli Toxin, GhoT

GhoT forms a type V toxin/anti-toxin system with GhoS protein in E.coli, in which GhoS protein degrades ghoT mRNA to ensure survival of the cell (Wang et al., 2012). Upon repression of ghoS gene transcription, ghoT mRNA is translated resulting in a ghost cell phenotype, where

290 GhoT toxin disrupts plasma membrane, thus leading to cell death. We expressed GhoT in 291 Rhodobacter under both semi-aerobic and anaerobic photoheterotrophic conditions. Since the 292 puc promoter has limited activity during semi-aerobic growth, the GhoT expression level is 293 expected to remain low. Consistent with low expression, there was not a noticeable phenotype 294 change for the semi-aerobically grown colonies (Fig. 9A). However, under anaerobic 295 photoheterotrophic conditions, where puc promoter was highly active, a distinct phenotype was 296 observed that was characterized by excessive biofilm formation, consistent with GhoT imposed 297 toxicity (Fig. 9B). To provide the further evidence for functional GhoT expression, the strain 298 expressing less toxic GhoT-F38R mutant was tested under both growth conditions, as well. The 299 stressed biofilm phenotype was nearly completely attenuated for both semi-aerobic and 300 anaerobic photoheterotrophic growth consistent with a greatly reduced toxicity for the mutant 301 toxin form. The observation of general stress but not death due to GhoT expression suggests that 302 high levels of intracellular membranes in Rhodobacter could buffer the toxic effects. The 303 purification of 7-Histidine tagged version of GhoT using cobalt or nickel affinity resins was not 
304 successful possibly due to its small size $(7.7 \mathrm{kDa}$ ) and extremely high isoelectric point (pI 10.7)

305 as estimated by isoelectric point calculator (Kozlowski, 2013).

306

307 DISCUSSION

308 Our results suggest that functional expression was achieved for at least four out of the

309 five of the diverse MPs tested. The purified protein levels, as summarized in Table II, were

310 superior to alternative expression hosts, where comparisons were available. More importantly,

311 the goal of maintaining functionality was confirmed for four of these proteins, where a functional

312 test was available. We attribute the successful expression to the high levels of intracellular

313 membranes in Rhodobacter as has been shown to improve membrane protein expression in

314 PAH1 mutants of the yeast, Yarrowia lipolytica, that display excess proliferation of endoplasmic

315 reticulum membranes (Guerfal et al., 2013). While Rhodobacter has been recognized for its

316 utility for MP expression, the photoheterotrophic growth mode has received minimal attention

317 because it is more difficult to implement. At the same time, the additional parameters of light

318 intensity, light quality, temperature and dissolved oxygen present a tremendous opportunity to

319 improve and optimize this system. Optimization was not addressed in this work in favor of

320 initially establishing a greater breadth of functional testing. Light driven degradation of antibiotic

321 selection marker, tetracycline, was not an issue in our expression studies, as we avoided this

322 problem using infrared LEDs as light source. Modification of the expression vector selectable

323 marker to avoid this problem has been demonstrated (Mather et al., 1995), but adoption of that

324 approach for this expression platform remains to be addressed in future studies. The individual

325 MP targets are discussed further below. 
Cyt-cy was chosen as a model protein known to be expressed at high levels reaching 50 $\mathrm{mg} / \mathrm{mL}$ (Laible et al., 2009). In this work, the expression titers were improved and functionality of this protein was evaluated by measuring its peroxidase activity using a chromogenic peroxidase substrate TMB. The measured activity was as $1.18 \pm 0.38 \mathrm{nmol} \mathrm{H}_{2} \mathrm{O}_{2} / \mathrm{min} / \mu \mathrm{mol}$ Cytcy, which was comparable to the other reported values in the literature for P450-type cytochromes (Kim et al., 2004). crystal structure has been determined. Both BcsA and BcsB proteins were reported to be necessary for the enzymatic activity (Morgan et al., 2013). We expressed a C-terminally 12-Histagged version of $\mathrm{Bcs} A$ and $\mathrm{BcsB}$ from a single $p u c$ promoter and purified with a yield reaching $1.5 \mathrm{mg} / \mathrm{L}$ culture, which significantly reduces the expression volume of $36 \mathrm{~L}$ reported for the $E$. coli expression system which yielded $0.15 \mathrm{mg}$ BcsAB per liter of culture. The complex was active as evidenced by in vitro cellulose synthesis assay using UDP-C ${ }^{14}$-glucose. The specific activity measured for this work in detergent micelles was $58 \mathrm{nmol} / \mathrm{mg} \mathrm{BcsAB} / \mathrm{min}$. Although this is significantly lower than previously reported BcsAB activity that was measured in 341 proteoliposomes using an enzyme-coupled assay (Omadjela et al., 2013), the results reported 342 here demonstrate a reduced activity by an order of magnitude in the absence of cyclic di-GMP, 343 the allosteric effector of $\mathrm{Bcs} A B$, as a demonstration of functionality that is consistent with other 344 previous reports (Morgan et al., 2014). The expression of the cellulose synthase represents an 345 increased challenge for Rhodobacter platform, since BcsAB is a much more complex multi346 subunit MP. Somewhat ironically, a large effort to express this important class of proteins from 347 more than 20 different species resulted in Rhodobacter sphaeroides BcsAB emerging as the 348 major expression success including the structure determination (Morgan et al., 2013). Although 15 
this is a homologous MP candidate, it represents considerable significance due to the ongoing

350 efforts to understand plant cell walls - including their use as a biofuel feedstock (Abramson et

351 al., 2010). It would be interesting to screen the expression of cellulose synthases from other

352 model organisms such as the plant Arabidopsis thaliana. The purified BcsAB amount was almost

353 an order of magnitude less compared to RsAqpZ, a homologous aquaporin water channel protein

354 (Erbakan et al., 2014), possibly due to the challenge of functional assembly of the multimeric

355 protein. Such assembly likely benefitted from expression in a homologous host as well as our

356 polycistronic construct, which would provide stoichiometric balance of the co-translated

357 subunits.

Human aquaporin 9 (hAQP9) is an aquaglyceroporin, which has permeability to water

359 and several other small-uncharged molecules (Tsukaguchi et al., 1999). Here, we expressed a

360 Rhodobacter codon-optimized hAQP9 gene under anaerobic photoheterotrophic conditions with

361 a yield around $0.2 \mathrm{mg} / \mathrm{L}$ as estimated by SDS-PAGE and Western-blotting. This level of purified

362 protein is 2-fold higher than Sf9 insect cell expression system (Viadiu et al., 2007). Functionality

363 was assessed by measuring the osmotic water permeability in phospholipid vesicles embedded

364 with purified hAQP9. The water permeability was directly proportional to the protein mass

365 fraction in liposomes indicating significant water transport by heterologously expressed hAQP9.

366 An assumption of 100\% incorporation and functionality of the expressed hAQP9 provides a

367 single channel permeability of $6.8 \times 10^{-14} \mathrm{~cm}^{3} / \mathrm{s}$, which is roughly 2 -fold lower than the original

368 report for E. coli AqpZ (Borgnia et al., 1999). However, as we have shown using fluorescently

369 tagged Rhodobacter AqpZ by means of fluorescence correlation spectroscopy, the reconstitution

370 efficiency of aquaporins in liposomes is severely reduced at higher protein to lipid ratios, which

371 results in significant underestimation of the actual water permeability (Erbakan et al. 2014). The 
372 success in achieving functional heterologous expression of a human aquaporin in Rhodobacter is

373 a significant accomplishment for the Rhodobacter expression platform and opens the opportunity

374 for further study of this exciting class of proteins. Although codon optimization of the hAQP9

375 gene may have contributed to reaching the highest heterologous expression level yet reported,

376 the titer remained significantly lower compared to structurally similar homologous aquaporin,

377 RsAqpZ. This emphasizes the utility of developing a breadth of MP expression platforms to 378 study this important class of proteins.

Occludin is a structural MP localizing in tight junctions of epithelial and endothelial cells 380 with many implications in breast, prostate and brain cancers (Feldman et al., 2005). Therefore, 381 understanding its function and structural properties is useful towards design of new cancer 382 therapeutics. A high level expression of occludin construct composed of transmembrane and C383 terminal domains is observed in our Rhodobacter system. The focus on transmembrane and C384 terminal domains was chosen because they have been reported to represent the critical functional 385 domains in tight junction formation and signaling through binding partners, respectively 386 (Feldman et al. 2005). Functional characterization of occludin is hampered by a lack of known 387 enzymatic or transport activity for this protein. Thus, a radio-ligand binding or complementation 388 assay remains to be performed for proven functionality.

389 GhoT is a small microbial toxin, responsible for ghost cell phenotype in E. coli (Wang et 390 al., 2013). When expressed in E. coli using the T7 expression system, it causes sudden death of 391 the cells precluding use of this host for production studies. The expression of GhoT in 392 Rhodobacter system was undertaken in part to test the hypothesis that the large membrane 393 content of Rhodobacter during photoheterotrophic growth might reduce the toxic effects of 394 GhoT. Indeed, Rhodobacter showed a higher level of tolerance to GhoT expression reaching 17 
395

396

397

398

399

400

401

402

403

404

405

406

407

408

409

410

411

412

413

414

415

416

417

$\mathrm{OD}_{660} \sim 3.0$. Although the biomass yield remained lower compared to the strains expressing other target MPs, GhoT expression strain survived and was associated with an expression-dependent mucoid phenotype. The subsequent efforts on expression quantification and purification were problematic due to high isoelectric point $(\sim 10.7)$ and small molecular weight $(\sim 7.7 \mathrm{kDa})$ of the protein.

The work with GhoT and occludin is an important reminder that achieving expression is only an initial step in the study of MPs, as their individual characteristics require extensive expertise in purification and subsequent functional characterization. In this study, we show not only versatility of Rhodobacter expression system but also functionality of the expressed proteins, which is critically important for studies requiring function such as biomimetic devices, high-throughput drug screening and drug delivery applications.

\section{CONCLUSIONS}

This preliminary success of the photoheterotrophic Rhodobacter MP expression platform invites additional improvements and optimizations. Besides optimization of light and dissolved oxygen, the expression vectors themselves were originally designed for semi-aerobic growth in the dark and warrant improvement. Light-sensitive tetracycline selectable marker and the requirement of conjugal plasmid transfer from $E$. coli are few of the cumbersome aspects of the system that could be readily improved. Even in the current unoptimized form, the tools developed in this work allow for rapid assessment of the expression level and the ease of purification; where assays are available for functional testing, the production of a particular protein in Rhodobacter deserves consideration. 


\section{Acknowledgments}

We thank Jeff Larsen for his efforts in molecular biology training. Deborah Hansen and

421 Philip Laible (Argonne National Labs. University of Chicago, Chicago, IL) kindly provided

422 Rhodobacter sphaeroides strains (ATCC17023 and PUC705-BA) and the expression vector

423 ( $p$ RKPLHT7). We also acknowledge Tucker Langseth and Cory Thomas for culturing assistance;

424 Hsin-Yao Cheng and Professor Thomas Wood (Penn State) for providing GhoT and GhoTF38R

425 genes; Juan Du for assisting with BcsAB activity assay; Penn State Institutes of Energy and

426 Environment for equipment support of TEM and stopped flow. This project was initiated with

427 funding from the Penn State's Grace Woodward Grants for Collaborative Research and

428 Medicine, which included providing the occludin codon-optimized gene construct. A fellowship

429 to B.R.C. from the Department of Chemical Engineering BioEndowment fund provided full time

430 summer research support at this early stage of assessment. An Advanced Research Project

431 Agency (ARPA-Electrofuels, \#DE-AR0000092) grant "Development of Rhodobacter as a fuels

432 production platform" to W.R.C. provided support for genetic transformation development work.

433 M.E. was supported throughout this work by a grant from the Turkish Republic, Ministry of

434 National Education. The Center for Lignocellulose Structure and Formation, an Energy Frontier

435 Research Center funded by the U.S. Department of Energy, Office of Science, and Office of

436 Basic Energy Sciences under Award Number DE-SC0001090 provided follow up support to

437 M.E. and characterization of Rhodobacter cellulose synthase. 
Tables

Table I. Vector constructs used in this study

\begin{tabular}{|c|c|c|}
\hline Construct & Description & Reference \\
\hline $\begin{array}{l}\text { pRKPLHT1 } \\
-c y t c y\end{array}$ & $\begin{array}{l}\text { Semi-aerobic expression of Rhodobacter capsulatus } \\
\text { Cytochrome-cy under control of puf promoter }\end{array}$ & $\begin{array}{l}\text { (Laible et } \\
\text { al., 2009) }\end{array}$ \\
\hline $\begin{array}{l}\text { pRKPLHT7 } \\
\text {-cyt cy }\end{array}$ & $\begin{array}{l}\text { Photoheterotrophic expression of Rhodobacter capsulatus } \\
\text { Cytochrome-cy under control of puc promoter }\end{array}$ & $\begin{array}{l}\text { (Laible et } \\
\text { al., 2011) }\end{array}$ \\
\hline $\begin{array}{l}\text { pRKPLHT7 } \\
-R s A q p Z\end{array}$ & $\begin{array}{l}\text { Photoheterotrophic expression of Rhodobacter sphaeroides } \\
\text { under control of puc promoter }\end{array}$ & $\begin{array}{l}\text { (Erbakan et } \\
\text { al., 2014) }\end{array}$ \\
\hline $\begin{array}{l}\text { pRKPLHT7 } \\
\text {-ghoT }\end{array}$ & $\begin{array}{l}\text { Photoheterotrophic expression of } E . \text { coli GhoT peptide under } \\
\text { control of puc promoter } \\
\text { ghoT_F*: } \\
\text { TAAAGTACTAGTGGAGGCCATTCATGGCACTATTCTCT } \\
\text { ghoT_R*: } \\
\text { GCCGCCAGATCTAAAGAGAGAAAAAAGTAATGCCAC }\end{array}$ & This study \\
\hline $\begin{array}{l}\text { pRKPLHT7 } \\
\text {-occludin }\end{array}$ & $\begin{array}{l}\text { Photoheterotrophic expression of transmembrane and C- } \\
\text { terminus of human occludin under control of puc promoter }\end{array}$ & This study \\
\hline $\begin{array}{l}\text { RKPLHT7 } \\
\text {-human } \\
\text { AQP9 }\end{array}$ & $\begin{array}{l}\text { Photoheterotrophic expression of human aquaporin } 9 \text { under } \\
\text { control of puc promoter }\end{array}$ & This study \\
\hline $\begin{array}{l}p R K P L H T 7 \\
-b c s A B\end{array}$ & $\begin{array}{l}\text { Photoheterotrophic expression of Rhodobacter sphaeroides } \\
\text { 2.4.1. cellulose synthase complex under control of puc promoter } \\
b c s A \_F \text { :GCATGTGGCGACTAGTGGAGGATTCCTAATGA } \\
\text { CCGTTCGAGCCAAGGC } \\
b c s A \_R \text { :GTCCATCAGTGGTGATGATGGTGATGGTGGTG } \\
\text { ATGGTGATGATGGTTCGACCCCCAGGCGACCGTGTT } \\
b c s B \_F \text { : } \\
\text { ATCACCACTGATGGACATGCGACTGCTGCCTTTC } \\
b c s B \_R: \text { GGTGGTGGTGAGATCCTTAAGTCATTTCAGGCC } \\
\text { CTTCCTCCG }\end{array}$ & This study \\
\hline
\end{tabular}


Table II. Membrane proteins expressed in Rhodobacter sphaeroides in the present study

\begin{tabular}{|c|c|c|c|c|c|}
\hline Protein & Class & Origin & Topology & Expression (mg/L) & Active? \\
\hline Cyt-cy & \begin{tabular}{|l} 
Heme \\
protein, \\
electron \\
transfer
\end{tabular} & $\begin{array}{l}\text { Rhodobacter } \\
\text { capsulatus } \\
(R . \text { cap. })\end{array}$ & $1 \mathrm{TM}$ & $\begin{array}{l}50 \text { in } R . \text { sph. (Laible et al., } \\
2009) 47 \text { in } R . \text { sph. Purified } \\
\text { (This study) }\end{array}$ & Yes \\
\hline $\mathrm{Bcs} A B$ & $\begin{array}{l}\text { Membrane } \\
\text { bound } \\
\text { cellulose } \\
\text { synthase }\end{array}$ & $\begin{array}{l}\text { Rhodobacter } \\
\text { sphaeroides } \\
\text { (R. sph.) }\end{array}$ & $\begin{array}{l}\text { BcsA:8TM } \\
\text { BcsB:1TM }\end{array}$ & $\begin{array}{l}0.2 \text { in E. coli (Morgan et al., } \\
2013 \text { ) } \\
1.5 \text { in R. sph. Purified (This } \\
\text { study) }\end{array}$ & Yes \\
\hline AQP9 & $\begin{array}{l}\text { Porin; water } \\
\& \text { glycerol } \\
\text { transporter }\end{array}$ & Homo sapiens & $6 \mathrm{TM}$ & $\begin{array}{l}\text { Not detectable (Oberg et al., } \\
2009 \text { ) } \\
0.1 \text { in } S f 9 \text { cells (Viadiu et al., } \\
2007 \text { ) } \\
0.5 \text { in } R . \text { sph. Purified (This } \\
\text { study) }\end{array}$ & Yes \\
\hline Occ & $\begin{array}{l}\text { Tight } \\
\text { junction } \\
\text { protein }\end{array}$ & Homo sapiens & $4 \mathrm{TM}$ & $\begin{array}{l}\text { Not determined (Neophytou et } \\
\text { al., 2007) } \\
7.5 \text { in R. sph. Purified (This } \\
\text { study) }\end{array}$ & ND \\
\hline GhoT & $\begin{array}{l}\text { Microbial } \\
\text { toxin }\end{array}$ & $\begin{array}{l}\text { Escherichia } \\
\text { coli }(\text { E. coli) }\end{array}$ & $2 \mathrm{TM}$ & ND & $\mathrm{P}^{*}$ \\
\hline
\end{tabular}


Abramson M, Shoseyov O, Shani Z. 2010. Plant cell wall reconstruction toward improved lignocellulosic production and processability. Plant Sci. 178:61-72.

Arechaga, I., Miroux, B., Karrasch, S., Huijbregts, R., De Kruijff, B., Runswick, M. J., \& Walker, J. E. (2000). Characterisation of new intracellular membranes in Escherichia coli accompanying large scale over-production of the b subunit of F1F(o) ATP synthase. FEBS Letters, 482(3), 215-219. http://doi.org/10.1016/S0014-5793(00)02054-8

Adams PG, Hunter CN. 2012. Adaptation of intracytoplasmic membranes to altered light intensity in Rhodobacter sphaeroides. Biochim. Biophys. Acta 1817:1616-27. http://www.ncbi.nlm.nih.gov/pubmed/22659614.

Bernaudat F, Frelet-Barrand A, Pochon N, Dementin S, Hivin P, Boutigny S, Rioux J-B, Salvi D, Seigneurin-Berny D, Richaud P, Joyard J, Pignol D, Sabaty M, Desnos T, Pebay-Peyroula E, Darrouzet E, Vernet T, Rolland N. 2011. Heterologous expression of membrane proteins: choosing the appropriate host. PLoS One 6:e29191. http://www.pubmedcentral.nih.gov/articlerender.fcgi?artid=3244453\&tool=pmcentrez\&rendertype= abstract.

Borgnia MJ, Kozono D, Calamita G, Maloney PC, Agre P. 1999. Functional reconstitution and characterization of AqpZ, the E. coli water channel protein. J Mol Biol 291:1169-1179. http://www.ncbi.nlm.nih.gov/pubmed/10518952.

Brown C, Leijon F, Bulone V. 2012. Radiometric and spectrophotometric in vitro assays of glycosyltransferases involved in plant cell wall carbohydrate biosynthesis. Nat. Protoc. 7:1634-50. http://dx.doi.org/10.1038/nprot.2012.089.

Cheng H-Y, Soo VWC, Islam S, McAnulty MJ, Benedik MJ, Wood TK. 2014. Toxin GhoT of the GhoT/GhoS toxin/antitoxin system damages the cell membrane to reduce adenosine triphosphate and to reduce growth under stress. Environ. Microbiol. 16:1741-54. http://www.ncbi.nlm.nih.gov/pubmed/24373067.

Curtis B. 2011. Development of Rhodobacter for the production of functional membrane proteins; The Pennsylvania State University. https://honors.libraries.psu.edu/paper/1965/.

Drews G, Golecki JR. 1995. Structure, molecular organization, and biosynthesis of membranes of purple bacteria. In: Blankenship, RE, Madigan, MT, Bauer, CE, editors. Anoxygenic Photosynth. Bact. Dordrecht: Springer Netherlands. Advances in Photosynthesis and Respiration, Vol. 2, pp. 231-257. http://www.springerlink.com/index/10.1007/0-306-47954-0.

Erbakan M, Shen Y, Butler PJ, Kumar M, Curtis WR, Grzelakowski M. 2014. Molecular cloning, overexpression and characterization of a novel water channel protein from Rhodobacter sphaeroides. PLoS One 9:e86830. 
http://www.pubmedcentral.nih.gov/articlerender.fcgi?artid=3909002\&tool=pmcentrez\&rendertype= abstract.

Feldman GJ, Mullin JM, Ryan MP. 2005. Occludin: structure, function and regulation. Adv. Drug Deliv. Rev. 57:883-917. http://www.ncbi.nlm.nih.gov/pubmed/15820558.

Guerfal, M., Claes, K., Knittelfelder, O., De Rycke, R., Kohlwein, S. D., \& Callewaert, N. (2013). Enhanced membrane protein expression by engineering increased intracellular membrane production. Microbial Cell Factories, 12(1), 122. http://doi.org/10.1186/1475-2859-12-122

Hanson DK, Mielke DL, Laible PD. 2009. Harnessing photosynthetic bacteria for membrane protein production. In: . Curr. Top. Membr. 1st ed. Elsevier Inc., Vol. 63, pp. 51-82. http://dx.doi.org/10.1016/S1063-5823(09)63003-9.

Jenney FE, Daldal F. 1993. A novel membrane-associated c-type cytochrome, cyt cy, can mediate the photosynthetic growth of Rhodobacter capsulatus and Rhodobacter sphaeroides. EMBO J. 12:1283-92. http://www.pubmedcentral.nih.gov/articlerender.fcgi?artid=413338\&tool=pmcentrez\&rendertype $=\mathrm{a}$ bstract.

Kim N, Jeong M, Choi S, Kang J. 2004. Peroxidase activity of cytochrome c. Bull. Korean Chem. Soc 25:1889-1892. http://pdf.easechem.com/pdf/32/1586a602-5e22-41db-aa61-493d0ed70efc.pdf.

Kozlowski LP. 2013. Calculation of protein isoelectric point. http://isoelectric.ovh.org/.

Laible PD, Mielke DL, Hanson DK. 2011. Production of Membrane Proteins. In: Robinson, AS, editor. Prod. Membr. Proteins Strateg. Expr. Isol. Weinheim, Germany: Wiley-VCH Verlag GmbH \& Co. KGaA. http://onlinelibrary.wiley.com/doi/10.1002/9783527634521.ch6/summary.

Laible PD, Scott HN, Henry L, Hanson DK. 2004. Towards higher-throughput membrane protein production for structural genomics initiatives. J. Struct. Funct. Genomics 5:167-72. http://www.ncbi.nlm.nih.gov/pubmed/15263855.

Laible PD, Mielke DL, Hanson DK. 2009. Foreign gene expression in photosynthetic bacteria. In: Hunter, CN, Daldal, F, Thurnauer, MC, Beatty, JT, editors. Purple Phototrophic Bact. The Netherlands: Springer. Advances in Photosynthesis and Respiration, Vol. 28, pp. 839-860. http://link.springer.com/10.1007/978-1-4020-8815-5.

Link AJ, Georgiou G. 2007. Advances and challenges in membrane protein expression. AIChE J. 53:752756. http://doi.wiley.com/10.1002/aic.11107.

Lundstrom K. 2004. Structural genomics on membrane proteins: mini review. Comb. Chem. High Throughput Screen. 7:431-9. http://www.ncbi.nlm.nih.gov/pubmed/15320710.

Majd S, Yusko EC, Billeh YN, Macrae MX, Yang J, Mayer M. 2010. Applications of biological pores in nanomedicine, sensing, and nanoelectronics. Curr. Opin. Biotechnol. 21:439-76. http://www.pubmedcentral.nih.gov/articlerender.fcgi?artid=3121537\&tool=pmcentrez\&rendertype= abstract. 
Mather MW, McReynolds LM, Yu CA. 1995. An enhanced broad-host-range vector for gram-negative bacteria: avoiding tetracycline phototoxicity during the growth of photosynthetic bacteria. Gene 156:85-88.

Morgan JLW, McNamara JT, Zimmer J. 2014. Mechanism of activation of bacterial cellulose synthase by cyclic di-GMP. Nat. Struct. Mol. Biol.:1-10. http://www.nature.com/doifinder/10.1038/nsmb.2803.

Morgan JLW, Strumillo J, Zimmer J. 2013. Crystallographic snapshot of cellulose synthesis and membrane translocation. Nature 493:181-6. http://dx.doi.org/10.1038/nature11744.

Myers J a, Curtis BS, Curtis WR. 2013. Improving accuracy of cell and chromophore concentration measurements using optical density. BMC Biophys. 6:4.

Myllykallio H, Jenney FE, Moomaw CR, Slaughter CA, Daldal F. 1997. Cytochrome c(y) of Rhodobacter capsulatus is attached to the cytoplasmic membrane by an uncleaved signal sequencelike anchor. J. Bacteriol. 179:2623-31. http://jb.asm.org/content/179/8/2623.short.

Neophytou I, Harvey R, Lawrence J, Marsh P, Panaretou B, Barlow D. 2007. Eukaryotic integral membrane protein expression utilizing the Escherichia coli glycerol-conducting channel protein (GlpF). Appl. Microbiol. Biotechnol. 77:375-81. http://www.ncbi.nlm.nih.gov/pubmed/17828601.

Nielsen CH. 2009. Biomimetic membranes for sensor and separation applications. Anal. Bioanal. Chem. 395:697-718. http://www.ncbi.nlm.nih.gov/pubmed/19636543.

Oberg F, Ekvall M, Nyblom M, Backmark A, Neutze R, Hedfalk K. 2009. Insight into factors directing high production of eukaryotic membrane proteins; production of 13 human AQPs in Pichia pastoris. Mol. Membr. Biol. 26:215-27. http://www.ncbi.nlm.nih.gov/pubmed/19384754.

Omadjela O, Narahari A, Strumillo J, Mélida H, Mazur O, Bulone V, Zimmer J. 2013. BcsA and BcsB form the catalytically active core of bacterial cellulose synthase sufficient for in vitro cellulose synthesis. Proc. Natl. Acad. Sci. U. S. A. 110:17856-61. http://www.pubmedcentral.nih.gov/articlerender.fcgi?artid=3816479\&tool=pmcentrez\&rendertype= abstract.

Rath A, Glibowicka M, Nadeau VG, Chen G, Deber CM. 2009. Detergent binding explains anomalous SDS-PAGE migration of membrane proteins. Proc. Natl. Acad. Sci. U. S. A. 106:1760-1765. http://www.ncbi.nlm.nih.gov/pubmed/19181854.

Remsen CC. 1978. Comparative subcellular architecture of photosynthetic bacteria. In: Clayton, RK, Sistrom, WR, editors. Photosynth. Bact. New York: Plenum Press, pp. 31-60.

Roy A, Shukla AK, Haase W, Michel H. 2008. Employing Rhodobacter sphaeroides to functionally express and purify human $\mathrm{G}$ protein-coupled receptors. Biol. Chem. 389:69-78. http://www.ncbi.nlm.nih.gov/pubmed/18095871.

Sarramegna V, Talmont F, Demange P, Milon A. 2003. Heterologous expression of G-protein-coupled receptors: comparison of expression systems from the standpoint of large-scale production and 
purification. Cell. Mol. Life Sci. 60:1529-1546. http://www.springerlink.com/openurl.asp?genre=article\&id=doi:10.1007/s00018-003-3168-7.

Sener MK, Olsen JD, Hunter CN, Schulten K. 2007. Atomic-level structural and functional model of a bacterial photosynthetic membrane vesicle. Proc. Natl. Acad. Sci. U. S. A. 104:15723-8. http://www.pubmedcentral.nih.gov/articlerender.fcgi?artid=2000399\&tool=pmcentrez\&rendertype= abstract.

Stevens TJ, Arkin IT. 2000. Do more complex organisms have a greater proportion of membrane proteins

Tate CG. 2001. Overexpression of mammalian integral membrane proteins for structural studies. FEBS in their genomes? Proteins 39:417-20. http://www.ncbi.nlm.nih.gov/pubmed/10813823.

Wang X, Lord DM, Cheng H, Osbourne DO, Hong SH, Sanchez-Torres V, Quiroga C, Zheng K, Herrmann T, Peti W, Benedik MJ, Page R, Wood TK. 2012. A new type V toxin-antitoxin system where mRNA for toxin GhoT is cleaved by antitoxin GhoS. Nat. Chem. Biol. 8:855-61. $\mathrm{http}: / /$ www.pubmedcentral.nih.gov/articlerender.fcgi?artid=3514572\&tool=pmcentrez\&rendertype= abstract.

Wang X, Lord DM, Hong SH, Peti W, Benedik MJ, Page R, Wood TK. 2013. Type II toxin/antitoxin MqsR/MqsA controls type V toxin/antitoxin GhoT/GhoS. Environ. Microbiol. 15:1734-44. http://www.pubmedcentral.nih.gov/articlerender.fcgi?artid=3620836\&tool=pmcentrez\&rendertype= abstract.

Yildirim M a, Goh K-I, Cusick ME, Barabási A-L, Vidal M. 2007. Drug-target network. Nat. Biotechnol. 25:1119-26. http://www.ncbi.nlm.nih.gov/pubmed/17921997.

Zeilstra-Ryalls J, Gomelsky M, Eraso JM, Yeliseev A, O’Gara J, Kaplan S. 1998. Control of photosystem formation in Rhodobacter sphaeroides. J. Bacteriol. 180:2801-9. http://www.pubmedcentral.nih.gov/articlerender.fcgi?artid=107241\&tool=pmcentrez\&rendertype=a bstract. 
Figure 1. Growth kinetics and biomass yield of Rhodobacter cultured under semi-aerobic and photoheterotrophic conditions. A: Growth kinetics depicted a lagtime for photoheterotrophic cultures (open symbols) possibly due to transition of the growth mode from semi-aerobic to photoheterotrophic. B: Photoheterotrophic growth yielded 4-fold higher biomass.

601

Figure 2. Growth kinetics and biomass yield of Rhodobacter cultured under semi-aerobic and photoheterotrophic conditions. A: Growth kinetics depicted a lagtime for photoheterotrophic cultures (open symbols) possibly due to transition of the growth mode from semi-aerobic to photoheterotrophic. B: Photoheterotrophic growth yielded 4-fold higher biomass

Figure 3. Cytochrome-cy (Cyt-cy) expression in Rhodobacter sphaeroides. A: 10 \% SDS PAGE gel of Cyt-cy purified via Ni-NTA column; SM: Solubilized total membrane fraction, FT: Flow-through from Ni-NTA column, 10-50: Wash fractions with imidazole concentrations between 10-50 mM; E: Elution with $500 \mathrm{mM}$ imidazole; M: Protein ladder. Cyt-cy is identified as two relevant bands at 25 and $35 \mathrm{kDa}$, corresponding to its two different conformations in SDS-PAGE gel, as reported in other studies (Jenney and Daldal, 1993; Myllykallio et al., 1997); B: Western-blot analysis of Cyt-cy detected by His-tag antibody in total cell (TC) and purified 614 protein $(\mathrm{E} 1)$

616 Figure 4. Peroxidase activity of Cyt-cy. A: Hydrogen peroxide reduction to water monitored 617 by absorbance shift of chromogenic peroxide substrate TMB from $280 \mathrm{~nm}$ to $655 \mathrm{~nm}$ at different 618 concentrations of Cyt-cy and radical scavenger sodium azide, $\mathrm{NaN}_{3}$. The conversion of TMB is 
619 severely affected by the increasing concentrations of azide. B: Peroxidase activity of $1 \mu \mathrm{M}$ Cyt-

620 cy was reduced to 40 and 25 per cent in the presence of $1 \mathrm{mM}$ and $5 \mathrm{mM} \mathrm{NaN}_{3}$, respectively. C:

621 Photograph showing the progression of the green color formation due to reduction of TMB. The 622 delay in the presence of increasing $\mathrm{NaN}_{3}$ is observed.

624 Figure 5. SDS-PAGE and Western-blot analysis of complex and in vitro cellulose synthesis

625 assay. A: BcsAB purification via metal affinity chromatography was monitored via SDS-PAGE.

626 Lanes M: Protein marker, SM: Solubilized membrane, FT: Flow-through from Co-NTA column,

627 20-50: Wash fractions with imidazole concentrations between 10-50 mM, E1\&E2: Elution with

$628500 \mathrm{mM}$ imidazole. Oxidized $\mathrm{BcsB}$ and BcsA are indicated around $100 \mathrm{kDa}$ and $80 \mathrm{kDa}$,

629 respectively. To the right, a Western-blot using His-tag antibody directed to C-terminal 12-His-

630 tag of BcsA confirmed that the faster migrating band was BcsA. B: BcsAB activity was

631 measured by UDP-C ${ }^{14}$-glucose incorporation assay. The scintillation count for the control devoid

632 of BcsAB complex is marked with black column. Cyclic di-GMP, allosteric effector of BcsAB

633 complex, had a large effect on the enzyme activity, as two orders of magnitude higher

634 scintillation count was measured in the presence of $12 \mu \mathrm{M}$ cyclic di-GMP.

635

636 Figure 6. SDS-PAGE and Western-blot analysis of human AQP9. Lanes correspond to the

637 samples collected from different stages of purification. FT: Flow-through from Co-NTA column;

$6380,25,50$ : wash fractions with corresponding imidazole concentrations 0-50 mM; M: Novex-

639 sharp prestained protein ladder; E: Elution with $500 \mathrm{mM}$ imidazole and WB is Western-blot

640 image of the elution detected using a polyclonal histag antibody. 
642 Figure 7. Water permeability of human AQP9 proteoliposomes. A: Functionality of the

643 purified hAQP9 was tested in proteoliposomes via stopped-flow light scattering. Liposomes were

644 rapidly mixed with an outward directed osmolyte, which results in water influx and increase in

645 scattered light at $90^{\circ}$. B: 3 to 5-fold increase was observed in water permeability for hAQP9

646 proteoliposomes compared to control liposomes devoid of hAQP9 at LPR 250 and 100,

647 respectively.

648

649 Figure 8. SDS-PAGE and Western-Blot analysis of Occludin. Lanes M: Protein marker; FT:

650 Flow-through from Co-NTA column; 10-50: Wash fractions with imidazole concentrations of

651 10-50 mM that were collected from Co-NTA column, one column volume at a time totaling 6

652 column volumes for each imidazole concentration; E1\&E2: Elutions with $500 \mathrm{mM}$ imidazole

653 collected from Co-NTA column one column volume at a time and WB is Western-blot image of

654 E1.

655

656 Figure 9. Phenotype test. $R$. sphaeroides strains harboring empty vector control, a mutated

657 version of the protein (GhoTF38R) and intact GhoT were grown on YCC agar plates

658 supplemented with $1 \mu \mathrm{g} / \mathrm{mL}$ tetracycline under semi-aerobic and photoheterotrophic conditions.

659 A: Semi-aerobic chemoheterotrophic growth, where puc promoter driving the protein expression

660 has a low baseline level activity. No significant phenotype change is noted among Control,

661 GhotF38R and GhoT. Although GhoT had some clear merged colonies possibly due to leaky

662 expression. B: Anaerobic photoheterotrophic growth conditions induce puc promoter for 
663 elevated GhoT expression. Control and GhoTF38R harboring strains display no phenotype;

664 however, a dramatic change in production of extracellular polymeric substances was observed 665 for GhoT expression strain.

666

667 

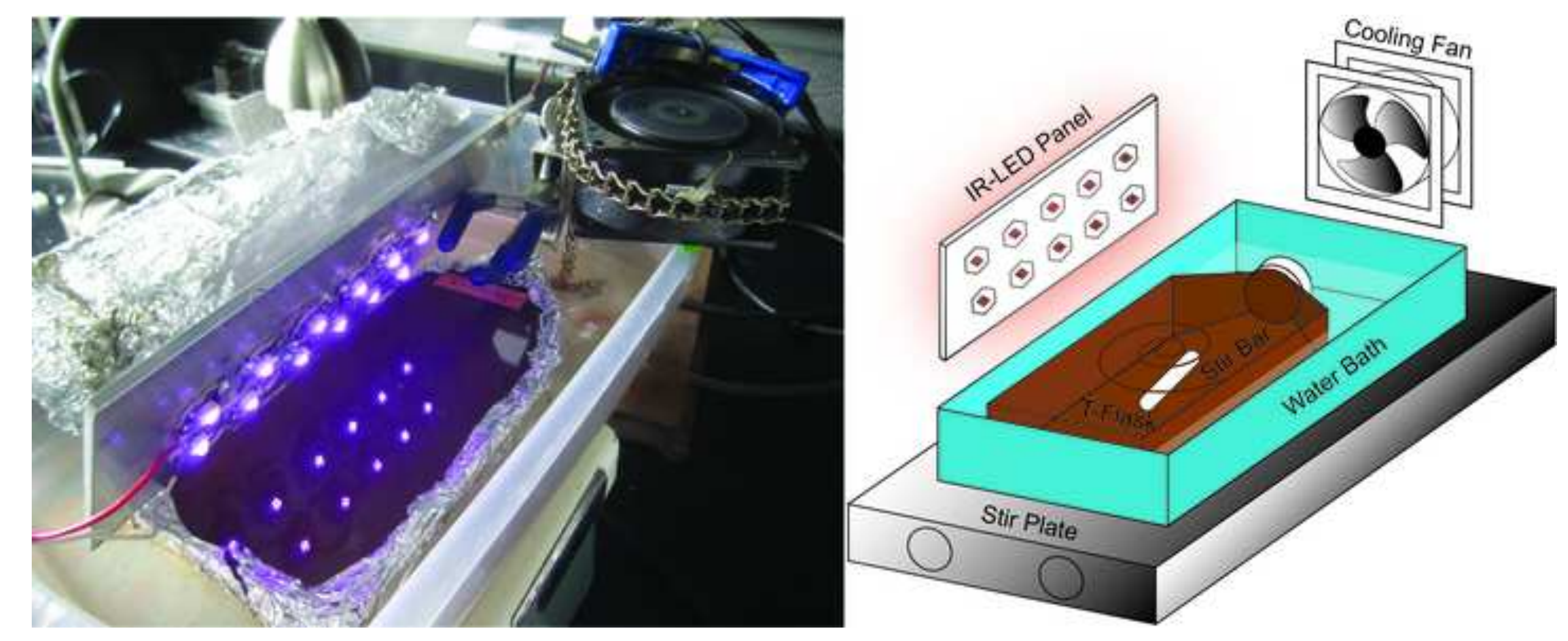
Figure 2

A

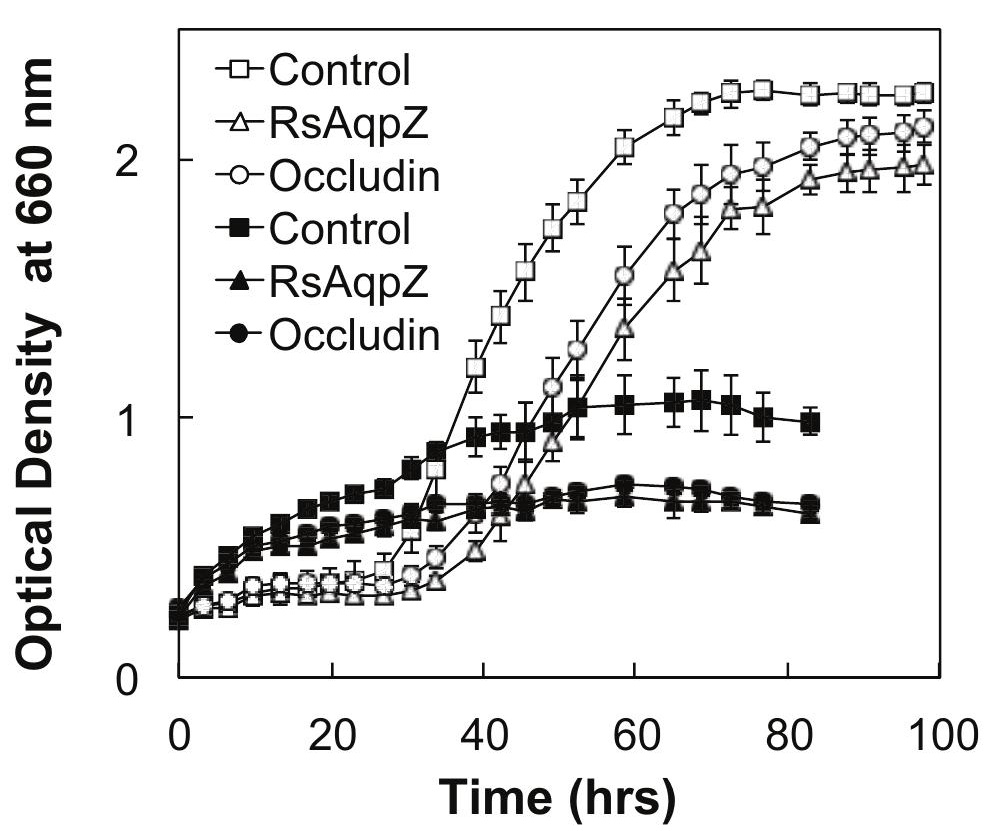

B

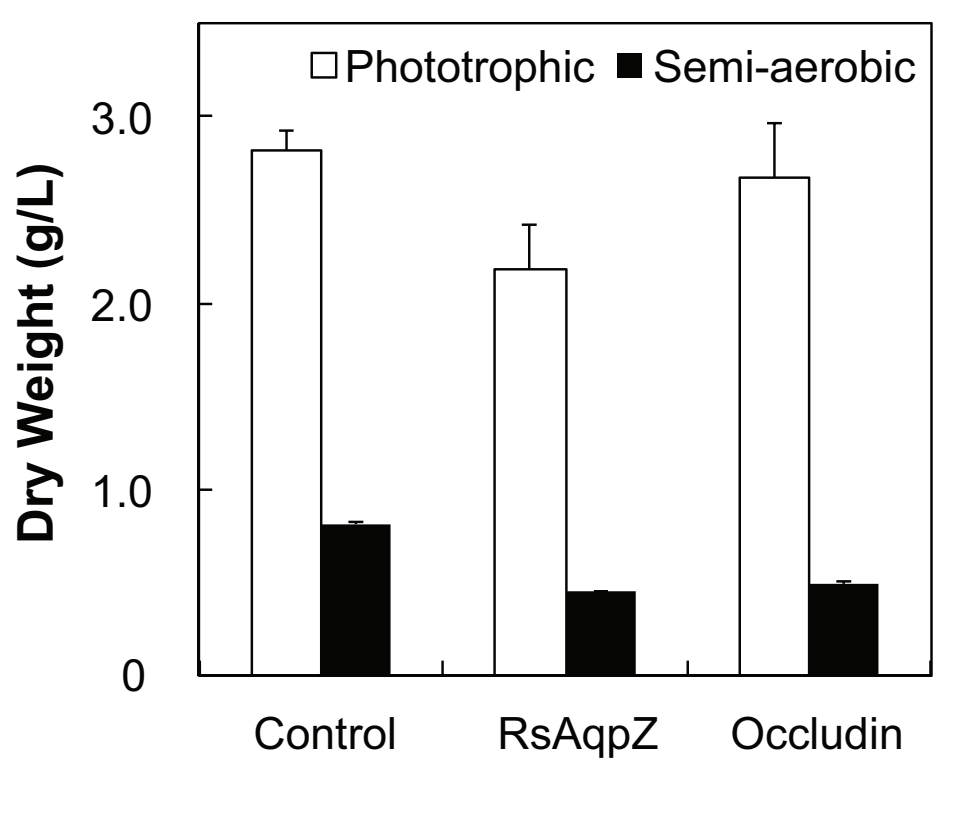


A $\begin{array}{llllllllll}\text { SM FT } & 10 & 20 & 30 & 40 & 50 & \text { E1 } & \text { E2 } & \text { M } & \text { kDa }\end{array}$
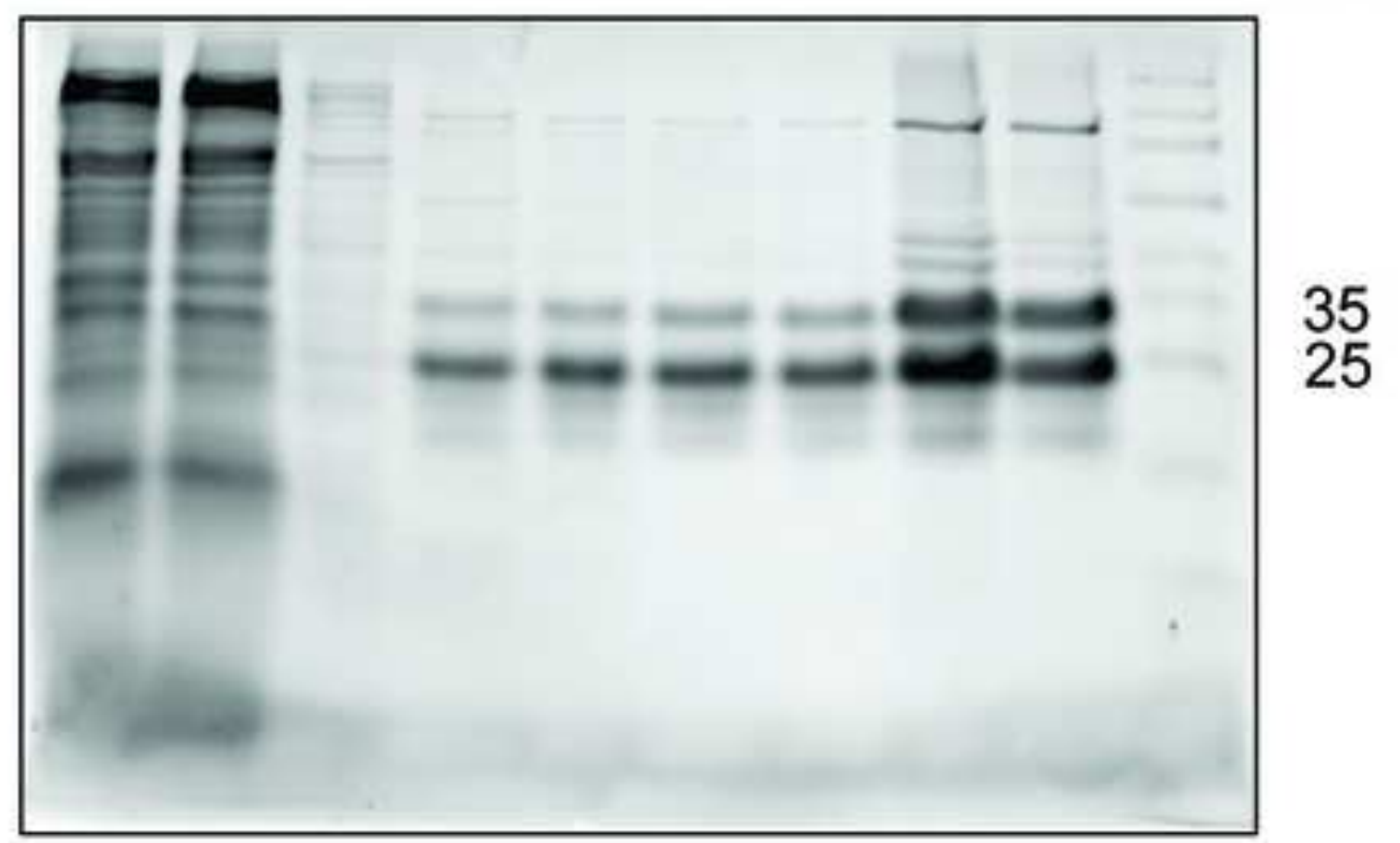

B

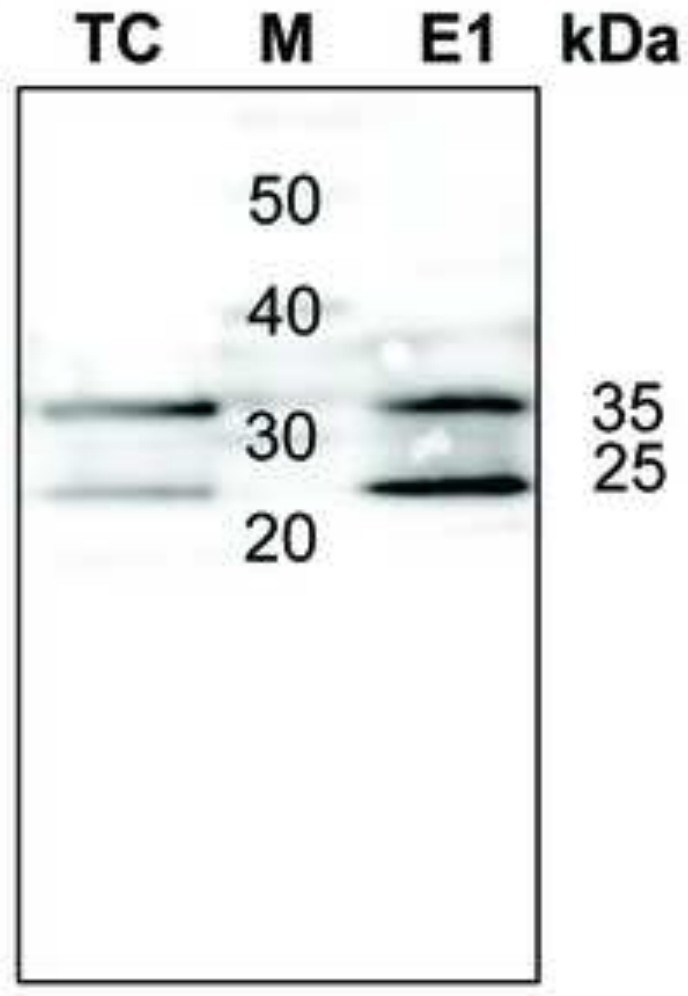


A $\quad$ M SM FT $20 \quad 30 \quad 40 \quad 50$ E1 E2 GF $\quad$ WB $\quad$ B
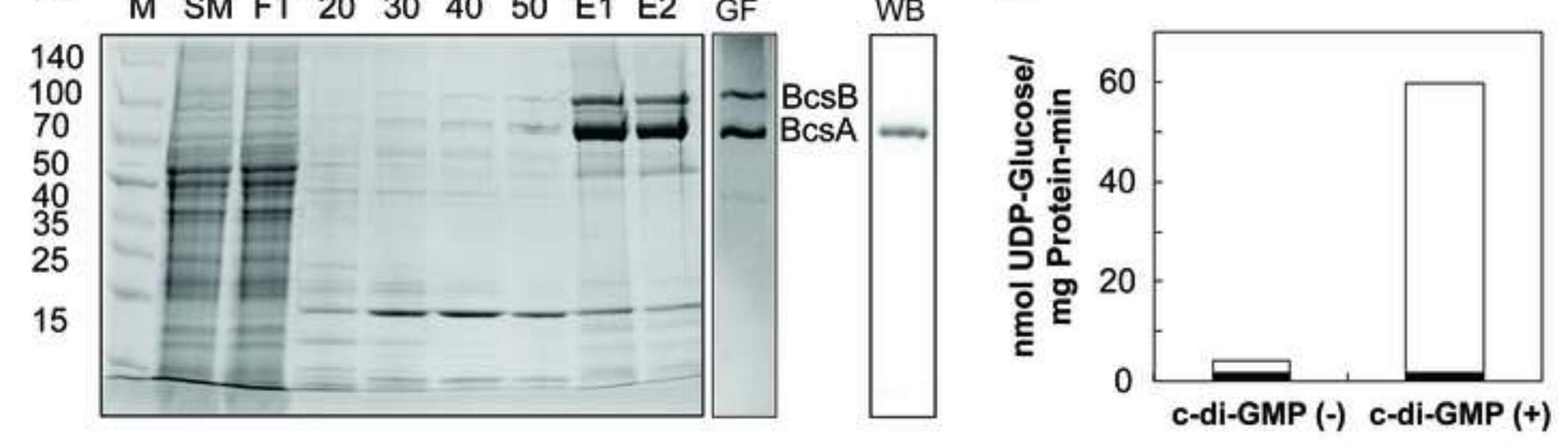
A

\section{B}
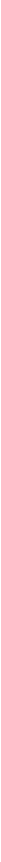

Figure 7 
$\underline{\underline{M}} \underline{\underline{F T}} \underline{10} \quad \underline{20} \quad \underline{\underline{30}} \quad \underline{40} \quad \underline{\underline{50}} \quad \underline{\underline{E} 1} \quad \underline{\underline{E}} \quad \underline{M}$
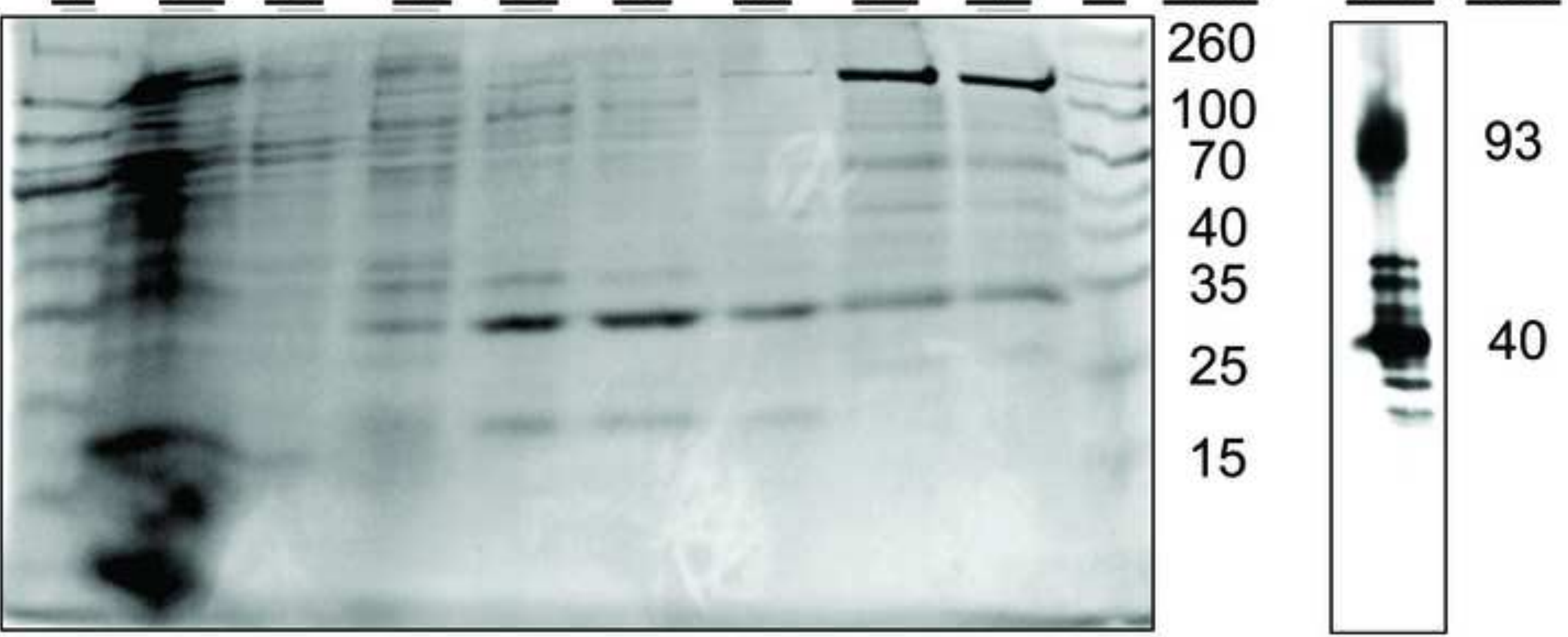

WB kDa

93

40 
A Semi-aerobic Chemoheterotrophic

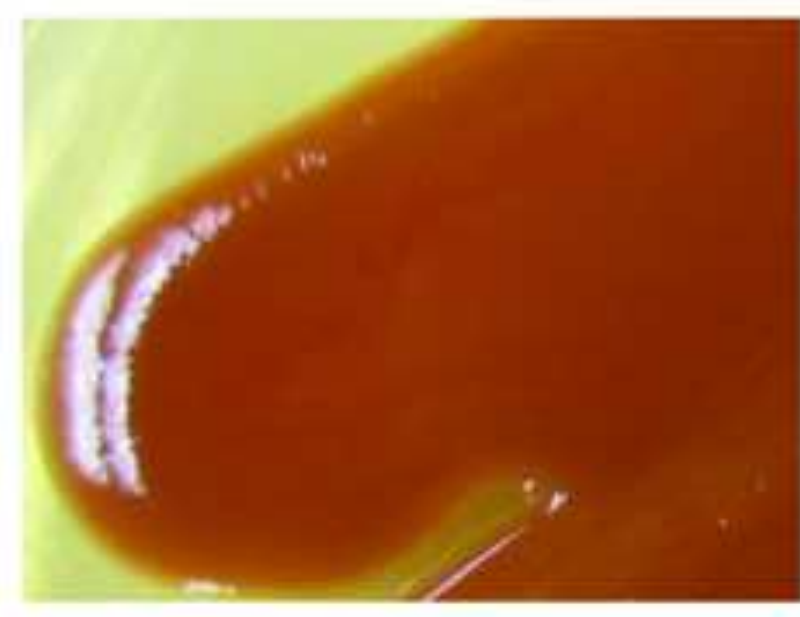

\section{Control}

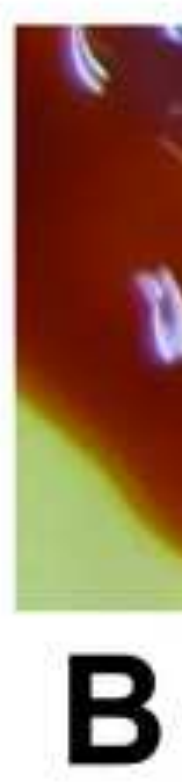

y 14

B
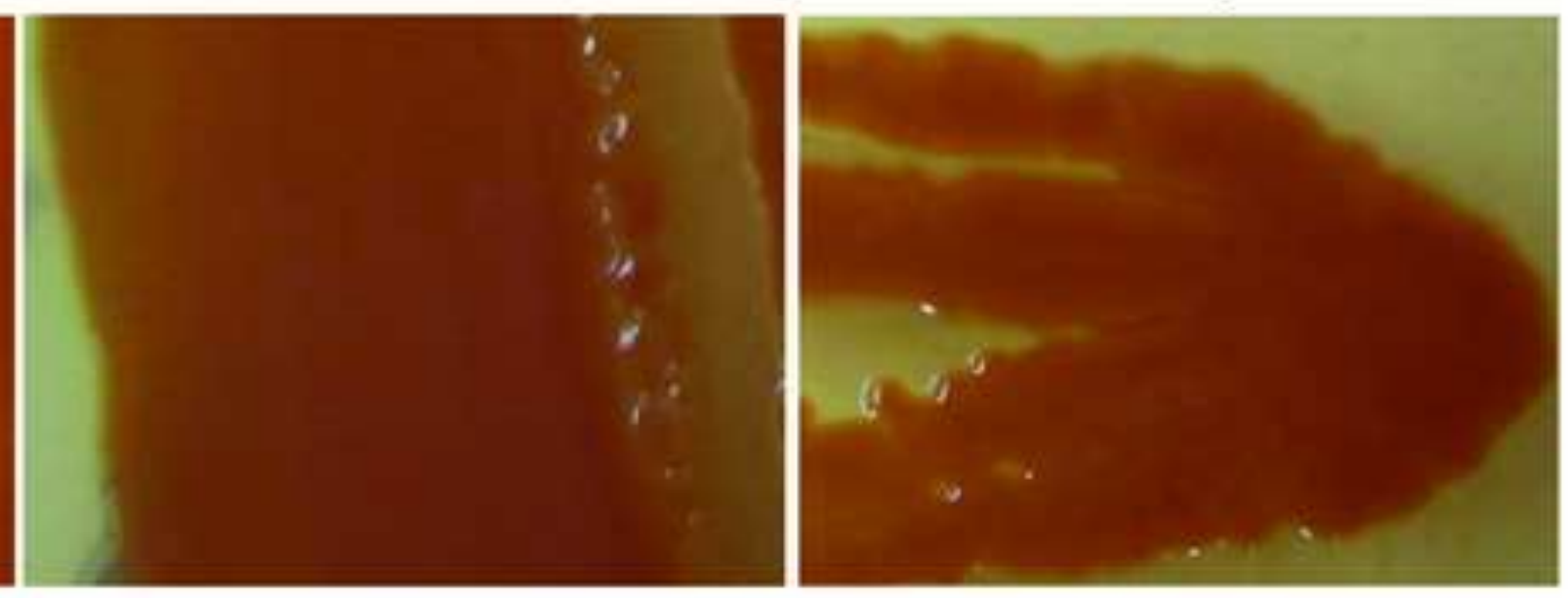

GhoTF38R

GhoT

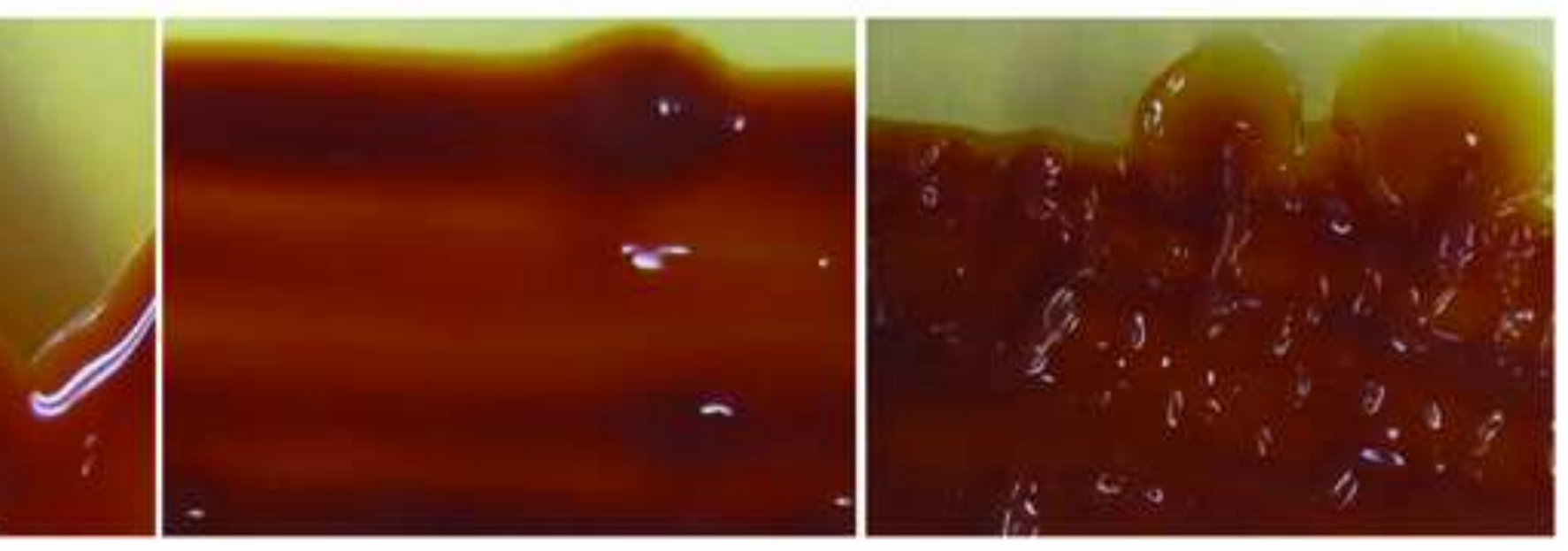

\section{Anaerobic Photoheterotrophic}

